\title{
An airway emergency and a preventable death: underutilisation of bronchoscopic intubation
}

\author{
Biplab Kumar Saha 다, 'Woon Hean Hean Chong (i] ${ }^{2}$
}

${ }^{1}$ Pulmonary and Critical Care Medicine, Ozarks Medical Center, West Plains, Missouri, USA

${ }^{2}$ Pulmonary and Critical Care Medicine, Albany Medical Center, Albany, New York, USA

\section{Correspondence to} Dr Biplab Kumar Saha; spanophiliac@yahoo.com

Accepted 5 March 2020

\section{DESCRIPTION}

A 34-year-old woman presented to the emergency department (ED) with worsening swelling of the face and neck for 2 days. The patient was evaluated in the ED a week earlier for a right molar tooth infection and was sent home on oral amoxicillin. The patient, however, experienced high-grade fever, gradual swelling of the submandibular and anterior neck, worse mouth and throat pain, and new-onset shortness of breath that progressed significantly, prompting her visit to the ED. During evaluation, she was visibly uncomfortable and in distress from the pain and shortness of breath. Her tongue was protruding with noticeable drooling, and she was using her accessory muscles of respiration. Her vital signs showed a temperature of $39.7^{\circ} \mathrm{C}$, a blood pressure of $157 / 98 \mathrm{~mm} \mathrm{Hg}$, a pulse of 127 beats/ min, a respiratory rate of 27 and an oxygen saturation of $92 \%$ on $4 \mathrm{~L}$ oxygen via nasal cannula. She had bilaterally reduced breath sound on auscultation but no audible stridor. An emergent CT of the neck with contrast was performed (figures 1 and 2). Following the return from the CT scan, the patient was noted to be tripoding and cyanotic with audible stridor. The decision was made to emergently intubate the patient to protect her airway. Rapid sequence intubation (RSI) was planned, and

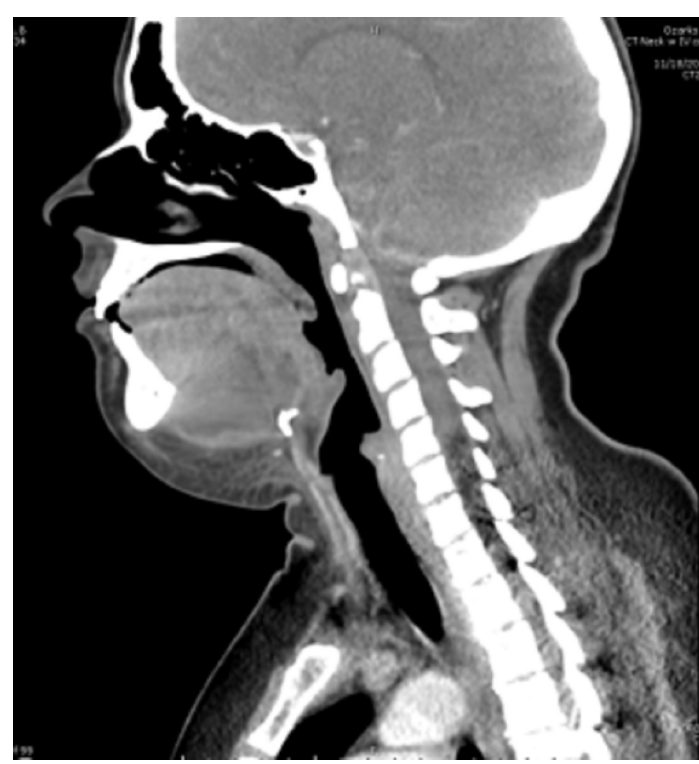
Limited 2020. No commercial re-use. See rights and permissions. Published by BMJ.

\begin{tabular}{l}
\hline To cite: Saha BK, \\
Chong WHH. BMJ Case \\
Rep 2020;13:e233883. \\
doi:10.1136/bcr-2019- \\
233883 \\
\hline
\end{tabular}

Figure 1 Sagittal view of the CT scan of the neck with contrast revealed profound swelling of the floor of the mouth and the subcutaneous tissue of the neck. There is severe swelling of the tongue with resultant superior and posterior displacement. There is no significant abnormality of the glottic area.

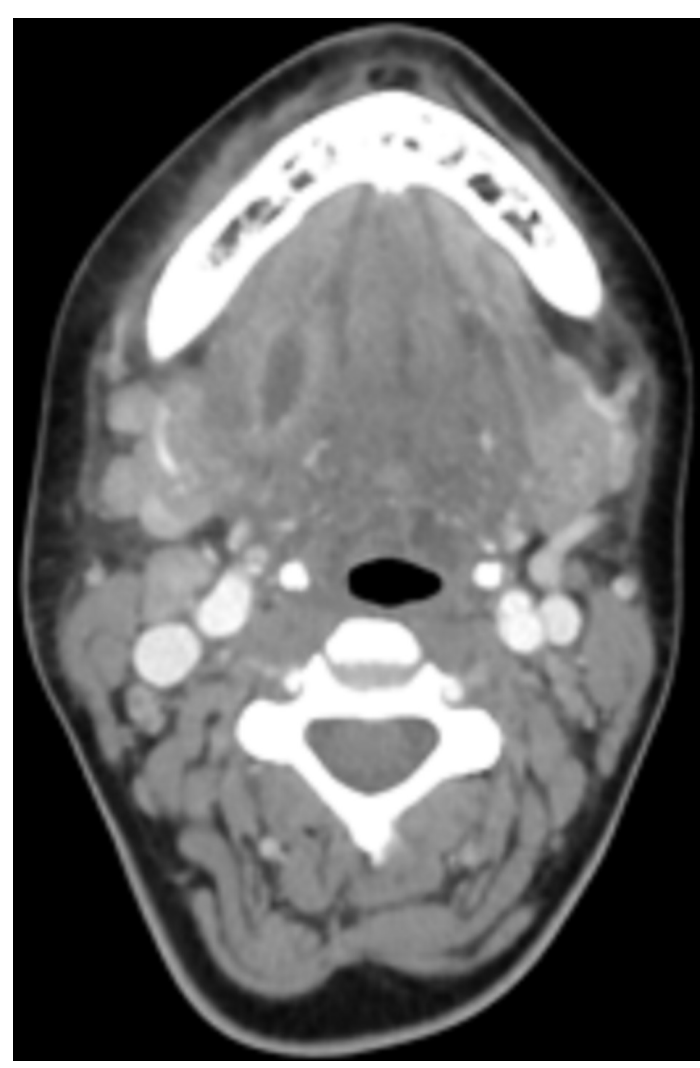

Figure 2 Axial view showing severe soft tissue swelling of the submandibular fossa and hypodensity suggestive of fluid collection in the right submandibular area.

the patient was paralysed with succinylcholine after inducing anaesthesia with etomidate. Multiple attempts by different operators with video-assisted laryngoscopy failed to secure the airway. A laryngeal mask airway could not be inserted. The patient could not be oxygenated with bag-mask ventilation, and her $\mathrm{SpO}_{2}$ was in the 70s. Bronchoscopic intubation attempts failed as the visualisation was poor secondary to the swelling and bleeding from prior traumatic attempts. An emergent cricothyroidotomy was undertaken but was unsuccessful due to the body habitus and profound neck inflammation. The patient lost her pulse while performing the cricothyroidotomy. Cardiopulmonary resuscitation was initiated following the Advanced Cardiovascular Life Support (ACLS) guideline. Unfortunately, an airway could not be secured, and despite all resuscitative attempts, the patient passed away.

This case provides the opportunity to highlight topics that could be the difference between life and death. First, Ludwig's angina is an aggressive and rapidly spreading infection of the submandibular 
space. An infected mandibular molar tooth is the responsible aetiology in two-third of the cases. ${ }^{1}$ The disease spreads quickly through the sublingual and submylohyoid spaces to involve the floor of the mouth bilaterally. The affected area becomes indurated and at an early stage without any fluctuation, which is suggestive of pus collection. The infection is polymicrobial, and antibiotics with anaerobic coverage are necessary for optimal therapy. Amoxicillin is often used for the treatment of an uncomplicated dental abscess, but if the abscess progresses to Luding's angina, it does not provide adequate antimicrobial coverage. In addition to providing referral for dental evaluation, appropriate education of the patient regarding the early signs and symptoms of treatment failure and development of Ludwig's angina is therefore crucial. Close follow-up is necessary for identification and possibly prevention of compromised airway.

The second and more critical issue is the evaluation and appropriate approach for airway management in patients with acute upper airway obstruction (UAO). For the ease of understanding, the UAO is divided into supraglottic, glottic and subglottic etiologies. This case would be representative of a supraglottic aetiology for acute UAO. With the infection of the submandibular space, there is significant swelling of the tongue (two to three times the original size) that results in anterior, superior and posterior displacement resulting in a substantial narrowing of the oropharyngeal and hypopharyngeal airway. This supraglottic obstruction can culminate in catastrophe if not identified early, and proper planning and intervention are not undertaken to establish a definitive airway for this life-threatening medical emergency. ${ }^{2}$

A thorough physical examination is of utmost importance to identify impending respiratory failure due to UAO. The use of accessory muscles of respiration, paradoxical abdominal movement with inspiration (due to diaphragmatic fatigue) and intercostal retraction are concerning developments. Inability to control upper airway secretion, manifested by drooling, development of stridor and cyanosis are ominous signs. Although cross-sectional imaging is very sensitive and can make a definitive diagnosis of Ludwig's angina, over-reliance on radiologic testing and failure to appreciate physical findings suggestive of impending respiratory failure might delay in the institution of appropriate care and result in worse outcomes. Our patient presented with fever, swelling of the submandibular area and anterior neck, protruded tongue, significant shortness of breath, use of accessory muscles and drooling, a constellation of signs and symptoms suggestive of impending respiratory failure from Ludwig's angina, and the decision to obtain a CT scan of the neck potentially delayed the attempt to establish a definitive airway.

RSI in the ED, especially with video-assisted laryngoscopy, has a high first-pass success rate. ${ }^{3}$ RSI involves fairly routine use of a paralytic agent and an induction agent for anaesthesia. However, in patients with Ludwig's angina, the use of a paralytic agent will result in loss of spontaneous breathing effort as well as the loss of pharyngeal and glossal muscle tone that can quickly worsen the obstruction. This might result in failed intubation and the inability to oxygenate with bag-mask ventilation. A supraglottic airway like a laryngeal mask airway might provide a temporary solution. An emergent cricothyroidotomy is the last resort in these situations and might be unsuccessful or associated with severe complications. The best and often under-appreciated and underused approach in this life-threatening situation is the use of awake fiberoptic bronchoscopy guided endotracheal intubation.

This approach avoids the use of neuromuscular blocking agents, thereby leaving the patients breathing efforts intact.
An anticholinergic agent like glycopyrrolate is used to decrease upper airways secretion. The oropharynx and hypopharynx are anaesthetised by nebulised and atomised lidocaine (4\%). The sensory nerve endings can be anaesthetised by placing $2 \%$ lidocaine gel in the glossoepiglottic and pharyngoepiglottic folds. Once the fiberoptic bronchoscope is introduced either through the mouth or the nose, $1 \%$ lidocaine can be instilled through the bronchoscope under direct visualisation, especially to the vocal cords to achieve adequate topical anaesthesia. The use of dexmedetomidine does not depress the respiratory drive and provide analgesia and sedation. The other benefit of this approach is not having to lay the patient down as the bronchoscope can be advanced while the patient is in a semirecumbent position. Had these approach been taken for this patient, there could have been a different outcome. Researchers have reported many cases of successful awake fibreoptic bronchoscopic intubation in patients with Ludwig's angina; however, it is still not a common practice in the ED. ${ }^{4}$ Awake cricothyroidotomy is another intervention that can be life-saving in this patient population. In conclusion, RSI is not always the answer for patients with acute supraglottic UAO, and all the options should be considered carefully before attempting RSI.

\section{Learning points}

- Ludwig's angina is characterised by rapid and aggressive, non-suppurative polymicrobial infection of the submandibular space that can rapidly cause upper airway compromise.

- Stridor and cyanosis are ominous signs and requires emergent intervention to protect from acute airway compromise. A thorough and careful physical examination can identify impending respiratory failure from upper airway obstruction compromise and obviate overreliance on imaging studies, which might potentially delay the accusation of a definitive airway.

- Awake fiberoptic bronchoscopic endotracheal intubation is the safest approach for this patient population as the use of neuromuscular blockers during rapid sequence intubation might result in failed attempts and has the potential for catastrophic outcome.

Contributors BKS was involved in direct patient care. BKS planned, collected data and prepared the initial manuscript. WHHC was involved in the preparation and finalisation of the manuscript.

Funding The authors have not declared a specific grant for this research from any funding agency in the public, commercial or not-for-profit sectors.

Competing interests None declared.

Patient consent for publication Next of kin consent obtained.

Provenance and peer review Not commissioned; externally peer reviewed.

\section{ORCID iDs}

Biplab Kumar Saha http://orcid.org/0000-0002-3595-8804

Woon Hean Hean Chong http://orcid.org/0000-0002-2070-3585

\section{REFERENCES}

1 Boscolo-Rizzo P, Da Mosto MC. Submandibular space infection: a potentially lethal infection. Int J Infect Dis 2009;13:327-33.

2 Eskander A, de Almeida JR, Irish JC. Acute upper airway obstruction. N Eng/ J Med 2019;381:1940-9.

3 Park L, Zeng I, Brainard A. Systematic review and meta-analysis of first-pass success rates in emergency department intubation: creating a benchmark for emergency airway care. Emerg Med Australas 2017;29:40-7.

4 Kulkarni AH, Pai SD, Bhattarai B, et al. Ludwig's angina and airway considerations: a case report. Cases J 2008;1:19. 
Copyright 2020 BMJ Publishing Group. All rights reserved. For permission to reuse any of this content visit https://www.bmj.com/company/products-services/rights-and-licensing/permissions/

BMJ Case Report Fellows may re-use this article for personal use and teaching without any further permission.

Become a Fellow of BMJ Case Reports today and you can:

- Submit as many cases as you like

- Enjoy fast sympathetic peer review and rapid publication of accepted articles

- Access all the published articles

Re-use any of the published material for personal use and teaching without further permission

Customer Service

If you have any further queries about your subscription, please contact our customer services team on +44 (0) 2071111105 or via email at support@bmj.com.

Visit casereports.bmj.com for more articles like this and to become a Fellow 